\title{
MEDIAÇÕES TECNO[I]LÓGICAS, SOCIALIZAÇÃO E CURRÍCULO
}

\section{TECNO [I] LOGICAL MEDIATIONS, SOCIALIZATION AND CURRICULUM}

VELLOSO, Luciana ${ }^{1}$

\section{RESUMO}

Buscando desenvolver um trabalho junto aos discentes da Faculdade de Educação do Curso de Pedagogia da UERJ, apresentamos algumas considerações sobre pesquisa em curso, tentando compreender os usos dos recursos tecnológicos e de uma vida cada vez mais em rede (CASTELLS, 1999, 2003, 2008, 2012; LEMOS e DI FELICE, 2014). Através de pesquisas de cunho etnográfico que se utiliza de observações, registros em caderno de campo e questionários, buscamos entender, a partir da ótica dos discentes, como avaliam seus níveis de deslocamento, pertencimento, inserção e imersão nesta lógica multimidiática, com destaque para as mídias digitais móveis. Com a pesquisa, procuramos avaliar elementos como as facilidades e dificuldades dos discentes para lidarem com os recursos tecnológicos, as cobranças docentes e a relação com o currículo do curso, as diferentes formas de comunicação entre as turmas e como tais elementos repercutem em sua socialização dentro do espaço universitário.

Palavras-chave: Novas tecnologias na educação; Mídias digitais e processos de ensino e aprendizagem; Processos de socialização.

\begin{abstract}
Aiming to develop a task with students of the Faculty of Education of Rio de Janeiro State University's Pedagogy Course, we present some considerations about our on-going research, where we try to understand the uses of technological resources and of an ever increasingly networked life (CASTELLS, 1999, 2003, 2008, 2012; LEMOS and DI FELICE, 2014). Through ethnographic research that uses observation, field notes and questionnaires, we sought to understand from the students' view how they evaluate their levels of displacement, belonging, insertion and immersion in this multimedia logic, with emphasis on digital mobile media. With the research, we tried to evaluate elements such as the students' ease and difficulty to deal with technological resources, teacher needs and their relation to the course curriculum, different forms of communication between the classes and how these elements reverberate in their socialization in the university environment.
\end{abstract}

KeYwORDS: New Technologies in education; Digital media and teaching and learning processes; Socialization processes.

\section{LINKANDO CONVERSAS INICIAIS}

No presente texto, apresentamos algumas considerações sobre pesquisa que temos desenvolvido junto aos discentes do curso de Pedagogia da Faculdade de

\footnotetext{
Programa de Pós-Graduação em Educação da Universidade do Estado do Rio de Janeiro (ProPEd/UERJ).e-mail: lucianavss@gmail.com
} 
Educação da Universidade do Estado do Rio de Janeiro (UERJ); um trabalho que articula o tripé currículo, tecnologias e diferentes espaços de sociabilidades e influências culturais, tentando compreender este espaço de interseção que envolve os usos dos recursos tecnológicos por parte dos estudantes.

Alguns são os autores que têm nos ancorado nesta empreitada. Para Di Felice (2014), por exemplo, a Internet é a quarta inovação tecnológico-comunicativa, seguida pela banda larga, pela Web 2.0 e atualmente já caminhando para a Web semântica. As inovações precedentes foram, no entendimento do autor, verdadeiras revoluções, como a passagem da oralidade para a escrita, a tipografia no século XV, com a invenção de Gutemberg e a eletricidade que trouxe consigo a mídia de massa (TV, cinema, imprensa, etc.).

Como avalia Castells $(2003,2013,2015)$ podemos considerar que, utilizando a metáfora da "galáxia", a internet é vista cada vez mais como o tecido de nossas vidas, tornando-se a base tecnológica para a forma organizacional da Era da Informação: a rede. A possibilidade de se alcançar um número maior de receptores é vista como fonte de esperança em um cenário de novas possibilidades de comunicação e construção de poder.

Para nos auxiliar em nossas reflexões, nos apropriamos de discussões como as de Mafessoli (2010), que com sua noção de sociabilidades nômades nos ajuda a pensar as interações que se constituem para além de nossas salas de aula, que conectam nossos discentes através dos recursos tecnológicos digitais, buscando entender até que ponto interferem e modificam nossas relações de ensino e aprendizado, não mais restritas a espaços físicos, mas que transcendem e até mesmo extrapolam os limites geográficos, territoriais e temporais.

As tecnologias quando utilizadas neste movimento de complementaridade em relação ao que se constrói nos espaços escolares, permitem que os processos de produção e troca de conhecimentos extrapolem os limites físicos, geográficos e temporais, subvertendo lógicas binárias de ensino e aprendizado e permitindo que as interações sociais se deem, de diferentes modos, para além do pré-requisito da presença física, pois a mesma não mais se fixa e com um simples aparelho de telefone conectado à Internet, podemos estar em vários lugares e executando tarefas das mais variadas, na atividade aparentemente paradoxal de se mudar de lugar inúmeras vezes, sem sequer se sair do lugar.

Com o auxílio de autores como Lévy (2000, 2007, 2008) identificamos que, com a fusão das telecomunicações, da imprensa, da edição, da televisão, do cinema e dos jogos eletrônicos em uma indústria unificada da multimídia, podemos presenciar um aspecto do que se costuma designar por revolução digital. Em suma, o novo nomadismo que caracteriza e interfere nas relações sociais contemporâneas se refere a um espaço invisível de conhecimentos, saberes, potências de pensamento que transformam qualidades do ser e maneiras de constituir a sociedade. 
John Urry $(2007,2010)$ analisa, a partir de uma perspectiva sociológica, como os novos avanços tecnológicos têm implicado novas maneiras de constituir e organizar identidades, através da possibilidade de viver experiências em vários espaços e tempos, consolidando o que denomina "Paradigma das Mobilidades" (URRY e ELLIOT, 2010). Os autores formulam um conceito que será central para esta pesquisa: "capital de rede", definido como a capacidade de movimento em diversos ambientes, incluindo a habilidade, competência e interesse em usar telefones celulares, SMS, e-mail, internet, Skype, etc.; acesso amplo a informações e contatos; equipamentos de comunicação, dentre outros.

Tendo em vista alguns desses nossos interlocutores, por meio de pesquisa de cunho etnográfico que se utiliza de observações, registros em caderno de campo e questionários, buscamos entender, a partir da ótica dos discentes da Faculdade de Educação do Curso de Pedagogia da UERJ, como avaliam seus níveis de deslocamento, pertencimento, inserção e imersão nesta lógica global mais ampla (em interlocução com o macro), mediados pelos recursos multimidiáticos, com destaque para as mídias digitais móveis. Com a pesquisa, procuramos avaliar elementos como as facilidades e dificuldades dos discentes para lidarem com os recursos tecnológicos, as cobranças docentes e a relação com o currículo do curso, as diferentes formas de comunicação entre as turmas e como tais elementos repercutem em sua socialização dentro do espaço universitário.

Desse modo, no intuito de desenvolver uma pesquisa de cunho etnográfico, destacamos a importância de acompanhar o cotidiano desse alunado e o cotidiano institucional, fazendo uso de técnicas muito caras ao campo da Antropologia, como caderno de campo, observações e entrevistas. Tura e Silva (2010) nos auxiliam a entender a etnografia como

um procedimento de pesquisa que se dirige a pequenas populações, em desenhos de pesquisas que não exigem tão alto grau de formalidade, mas que pretendem priorizar os contatos pessoais e as relações face a face (TURA e SILVA, 2010, p.72).

As autoras recomendam a permanência no campo de investigação por um tempo mais prolongado, em função da necessidade de um contato mais próximo entre o/a pesquisador/a e com os sujeitos do estudo. Isso possibilita um melhor entendimento das redes de significados partilhados pelo grupo.

É ainda Tura (2011) quem nos auxilia a entender os processos que envolvem tanto a observação, quanto o registro e a análise do que, em campo, é apreendido. A autora evidencia que uma observação minuciosa dos comportamentos e sua recorrência implicam que sua compreensão se dê no contexto das relações e condições sociais de sua produção. 
DOI: $10.12957 /$ e-mosaicos.2017.30009

\section{CONTEXTUALIZANDO RELAÇõES MACRO E MICRO}

Cada vez mais os alunos e alunas de diferentes instituições educacionais têm se utilizado de tecnologias, sobretudo digitais, para entrar com contato com o mundo. O mundo de fato parece caber em nossas mãos, expressando o que Jenkins (2009) anunciava ao tratar da suposta cultura da convergência, quando mídias tradicionais como nossas antigas lousas, coexistem no mesmo espaço com as mídias atuais, mais participativas e supostamente interativas, como tablets, Iphones, netbooks, pendrives, dentre outros recursos e suportes que tendem cada vez mais a convergir para um só com diversas possibilidades.

Com esses dispositivos, é possível acessar, interagir, produzir, publicar em diferentes tempos e lugares, criando-se um contexto de "comunicação ubíqua", que se dá em toda parte (PRIMO, 2008, p. 61) e abre o fluxo comunicacional em todas as direções, com a possibilidade de qualquer pessoa, em qualquer lugar, poder participar e trabalhar. A relação perto e longe se esgarça, pois a participação e a colaboração independem dos contatos físicos, sendo descentrada e desterritorializada (BONILLA; PRETTO, 2015).

O que se destacam são coletivos que vão se engajando, colaborando, participando e criando. Reconhece-se, assim, que todos os cidadãos podem ser autores, uma vez que podem criar, produzir e compartilhar bens imateriais, implicando novas regulamentações em torno das licenças de autor, o que possibilita a criação de grupos de mídias independentes que atuam ativamente na criação e conteúdo alternativo ao que surge nos grandes veículos, desenvolvendo estratégias bastante criativas para se conectar e expressar no contexto digital (JENKINS, FORD e GREEN, 2014).

Por outro lado, o fluxo digital da rede pode ser visto por dois lados: a rede amplia a liberdade de expressão e expande a capacidade de interação entre as pessoas. Entretanto, ela também é uma rede cibernética de comunicação e controle. Ao mesmo tempo em que se constitui um repositório de informações jamais visto na história da humanidade, nunca fomos tão controlados (PRETTO, 2013, p. 41).

Desse modo, justificamos importância de questionarmos até que ponto os estudantes de Pedagogia do curso de Pedagogia da UERJ, muitos e muitas ou futuros docentes ou já exercendo o ofício, se utilizam e se apropriam de recursos tecnológicos de informação e comunicação como Smartphones, internet, aplicativos de conversas instantâneas etc.; como se dão seus acessos a informações e contatos; se dispõem de equipamentos de comunicação; como e onde se encontram para estudar e realizar tarefas conjuntas, seja virtualmente ou fisicamente; como negociam seu tempo para lidar com as demandas do curso universitário e em que medida o uso desses recursos tecnológicos contribui para essas negociações.

Na busca de mapear essas diferentes mobilidades e como se dão, buscamos observar os movimentos de inclusão e exclusão que as tecnologias móveis e seus usos em sala de aula e em diferentes espaços ligados à vida universitária podem 


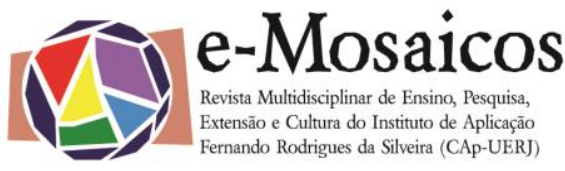

DOI: $10.12957 /$ e-mosaicos.2017.30009

propiciar, a partir da ótica dos próprios discentes. Buscamos operar a partir de lógicas não binárias, como o ter ou não ter informação, pois o acesso às tecnologias implica gradações. O fato de não possuir um computador em casa não implica necessariamente exclusão, já que acesso pode se dar por outros caminhos, como trabalho, escola, lan houses, dentre outros (PRETTO, 2011).

Para contextualizarmos o lócus de nossa pesquisa, o curso de Pedagogia da Faculdade de Educação da UERJ (campus Maracanã) é um dos cursos que abriga, além de muitas atividades de extensão e cursos de pós-graduação lato-sensu, um curso de pós-graduação stricto-sensu (com cursos de mestrado acadêmico e doutorado acadêmico), o Programa de Pós-graduação em Educação (ProPEd), avaliado com a nota máxima pela CAPES. Também dois outros cursos de pósgraduação stricto-sensu de caráter multidisciplinar da UERJ, funcionam no espaço da Faculdade de Educação e contam com a participação de seus professores: o Programa de Pós-Graduação em Políticas Públicas e Formação Humana (PPFH) e o Programa de Pós-graduação em Meio Ambiente (PPG-MA). A Faculdade de Educação oferece, ainda, Curso de Pedagogia à distância, através do Consórcio CEDERJ/CECIERJ e oferece disciplinas e estágios obrigatórios da área pedagógica para as demais Licenciaturas que fazem parte da UERJ. Essa convivência resulta em um diálogo fértil entre graduação e pós-graduação, na Faculdade de Educação, com ganhos expressivos para a formação dos alunos desses cursos.

A Faculdade de Educação oferece os cursos de Pedagogia nas modalidades Presencial e Semipresencial. Além disso, é responsável pelo Módulo Pedagógico de todos os Cursos de Licenciatura oferecidos pela UERJ no campus Maracanã também nas modalidades Presencial e Semipresencial. As principais formas de ingresso ao curso presencial é pelo Vestibular da UERJ e para o curso semipresencial pelo Vestibular do Consórcio Cederj.

A UERJ foi pioneira na adoção do sistema de reserva de vagas em função de um projeto de lei estadual com reserva de $50 \%$ de suas vagas no vestibular de 2003 para estudantes que cursaram o ensino médio em escolas da rede pública. Neste ano foram realizados dois concursos distintos, ambos com inclusão de afrodescendentes, porém sem o corte socioeconômico. Este processo foi modificado pela Lei no 4151, promulgada em 4 de setembro de 2003, tendo os primeiros alunos ingressados no Vestibular 2004. Como política de permanência para os estudantes oriundos de reserva de vagas a Universidade desenvolve o Programa de Iniciação Acadêmica (PROINICIAR) oferecendo disciplinas instrumentais, oficinas e atividades culturais. Além das atividades acadêmicas estes alunos recebem a Bolsa Permanência, atualmente no valor de $\mathrm{R} \$ 450,00$ (quatrocentos e cinquenta reais), durante todo o curso universitário e parte do material didático para realização das suas atividades.

O curso de Pedagogia conta com equipamentos multimídia (projetores e computadores) em quase todas as salas do décimo segundo andar, embora a manutenção não seja feita com a periodicidade demandada. Ademais, os computadores são para uso exclusivo dentro das salas (geralmente apresentações de 
trabalhos) e o Laboratório de Informática do andar, atualmente, encontra-se em desuso. Os computadores que os/as alunos/as costumeiramente acessam se encontram ou na biblioteca, que conta com cinco netbooks conectados à Internet, ou laboratórios que ficam em outros andares do prédio do Pavilhão Central Reitor João Lyra filho. As bibliotecas da UERJ estão vinculadas ao sistema da Rede Sirius ${ }^{2}$, que tem sua origem ligada à própria Universidade ${ }^{3}$. 0 acervo pode ser consultado digitalmente e retirado para empréstimo e/ou consulta local nas diferentes unidades físicas dos campi da UERJ, que englobam a Rede.

Ainda em termos de espaço físico, vale destacar que além de salas temáticas, como os ateliês de História da Educação - sala que ambienta uma sala de aula do início do século XX - e de Filosofia da Educação. Além disso, conta com uma ampla sala equipada com computadores para uso dos alunos disponível para todo o Curso, mas, em especial, para as disciplinas sobre Tecnologias e Educação (geralmente utilizadas pelos discentes unicamente no horário das aulas). Há salas destinadas aos encontros dos grupos de pesquisa e estudos específicos, coordenados por professores do curso.

Quanto aos laboratórios, constata-se a presença de três, quais sejam: Laboratório de Educação e Imagem, Laboratório de Educação Online e Laboratório de Educação Matemática. São utilizados mais para reuniões de grupos de pesquisa. Não possuem tamanho suficiente para comportar turmas de cerca de 45 alunos/as, que iniciam no começo do curso.

Na UERJ, os estudantes de Pedagogia são, em sua grande maioria, estudantes que conciliam estudo e trabalho, além de outras múltiplas funções. Os estudos fazem parte delas, não necessariamente sendo a prioridade muitas vezes por questões financeiras. Conciliar casa/trabalho/estudos nem sempre se constitui em tarefa das mais simples e conforme indica o estudo de Souza e Silva (2003), são diversos os fatores que contribuem para que uns e não outros, mesmo oriundos de camadas populares e condições análogas, possam se destacar e concluir seus estudos universitários. Como variáveis que se destacam, o autor sinaliza elementos como "competência cognitiva", "inteligência institucional" que vai sendo adquirida ao longo do curso e saber "jogar as regras do jogo" do ambiente acadêmico, apropriando-se das mesmas a seu favor.

\footnotetext{
${ }^{2}$ Fonte: http://www2.datauerj.uerj.br/catalogacao.html. Disponível em: http://www2.datauerj.uerj.br/ pdf/DATAUERJ_2016.pdf . Acesso em: 02 de fevereiro de 2017.

${ }^{3}$ A Rede Sirius nasceu da fusão das Faculdades de Ciências Médicas, de Direito, de Ciências Econômicas e de Filosofia, Ciências e Letras. Ao longo desses anos, as bibliotecas da UERJ sempre acompanharam a evolução histórica da Universidade, tanto no âmbito acadêmico quanto no organizacional. Fundamentada no trabalho em equipe, a Rede Sirius busca investir na modernização das suas bibliotecas visando o aprimoramento do suporte às atividades de ensino, pesquisa e extensão da Universidade. Fonte: http://www.rsirius.uerj.br/novo/index.php/institucional/sobre-arede-sirius/historico. Acesso em: 20/01/2017.
} 
DOI: $10.12957 /$ e-mosaicos.2017.30009

Tendo este pano de fundo em vista, passamos agora a apresentar o material que pudemos produzir ao longo de dois semestres de contato com estes estudantes.

\section{APRESENTANDO ALGUNS DADOS PRODUZIDOS}

Antes de iniciar a exposição do material que pudemos produzir ao longo da pesquisa, vale destacar que esta se desenvolveu ao longo dos períodos de 2016.1 e 2016.2 na UERJ, em um contexto de interrupções de calendário, faltas de pagamentos de docentes, técnicos e bolsas de alunos. Além disso, vale fazer um panorama geral da falta de condições infraestruturais pela qual a Universidade vem atravessando, algo que se agravou ainda mais no final do semestre de 2016.2. Os elevadores funcionavam precariamente, o restaurante universitário se encontrava fechado, os serviços de limpeza reduzidos os funcionários técnico-administrativos em greve.

Dito isto, em termos metodológicos, fizemos uso, além de observações sistemáticas de diferentes espaços do curso de Pedagogia da UERJ, também de registros em diário de campo. Foram, ainda, aplicados questionários em uma amostragem de discentes que consideramos não representativa da totalidade e que não nos permite fazer generalizações, mas nos ajuda a ter um panorama preliminar de como está a relação entre estudantes e recursos tecnológicos. Destacaremos, a seguir, alguns aspectos do material já produzido.

Os 40 questionários ${ }^{4}$ respondidos foram fruto de encontros presenciais, nos quais fazíamos uma breve apresentação da pesquisa e seu intuito. Com a concordância dos discentes, os questionários eram preenchidos nos intervalos das aulas, no espaço do Centro Acadêmico do curso de Pedagogia, na cantina e nos bancos do hall do curso, local de grande movimentação de docentes e discentes.

Os depoimentos coletados nos questionários aplicados com discentes do curso de Pedagogia da UERJ gravitam em torno de temáticas como relação com as novas redes, aplicativos e programas de comunicação digitais; facilidades e dificuldades para o uso das novas tecnologias dentro e fora da Universidade; relação entre aceitação ou não dos docentes para com o uso das novas tecnologias em sala e fora dela e se sentiam falta de uma formação que estivesse mais integrada ao uso das novas tecnologias na Universidade.

Dos quarenta $(\mathrm{N}=40)$ alunos e alunas que responderam o questionário, vinte e dois eram estudantes do curso noturno ${ }^{5}$ de Pedagogia da UERJ, sendo trinta e dois $(\mathrm{N}=32)$ do sexo feminino e sete $(\mathrm{N}=7)$ do sexo masculino. Buscamos nos deter em discentes de períodos variados do curso, para ter uma visão mais ampliada, tanto dos que estão iniciando, quanto dos que já estão chegando ao final da graduação.

\footnotetext{
${ }^{5}$ No presente trabalho, são apresentados dados relativos a questionários aplicados com estudantes do curso noturno, em função de ser este o turno no qual a docente e as alunas bolsistas que fazem parte da pesquisa se inserem.
} 
Suas faixas etárias concentravam-se em sua maioria entre dezoito e trinta anos, o que confere ao grupo entrevistado um perfil jovem. Vinte e nove alunos/as $(\mathrm{N}=29)$ nesta faixa etária, além de três alunas e dois alunos $(\mathrm{N}=5)$ que declararam ter mais de quarenta anos. Os demais não preencheram este campo.

Uma de nossas questões iniciais dizia respeito às experiências com o uso de recursos tecnológicos durante o Ensino Médio. Nove $(\mathrm{N}=9)$ discentes afirmaram que se recordam de terem realizado pesquisas na Internet para os trabalhos que eram solicitados. Das respostas, o que nos ficou bem evidente foi que, por mais que as escolas incentivassem o uso de computadores e outros recursos, este não se dava dentro de seu espaço. Alguns discentes trazem lembranças de aulas que se utilizavam de vídeos e materiais que estavam muito mais atrelados a aulas expositivas do que ao estímulo pela busca de conteúdos para além do que comportavam as disciplinas.

Entre os entrevistados treze $(\mathrm{N}=13)$ fizeram curso pré-vestibular para ingressar na UER], sendo esta a primeira graduação de todos eles. Observamos que vinte e oito $(\mathrm{N}=28)$ dos/as entrevistados/as realizam atividades remuneradas, sendo que vinte e um $(\mathrm{N}=21)$ informaram que trabalham na área de educação, ou com docência ou estágio em escolas.

Em termos de reconhecimento da importância de se conhecer e utilizar os recursos digitais percebemos a unanimidade nas respostas. Foi recorrente a assertiva de que o domínio das ferramentas é cada vez mais necessário e presente não somente em suas interações sociais mais amplas, mas especificamente no caso que aqui nos mobiliza, para finalidades acadêmicas.

As respostas indicaram que os docentes possuem a prática de fazer diversas solicitações de atividades nas quais estes usos e domínios são necessários. Por outro lado, também foi usual o reconhecimento de que sentem falta de um suporte e apoio, sobretudo aos que não dominam alguns programas mais demandados. Para dois discentes, a Universidade acabou sendo o elemento que fez com que percebessem este hiato em suas formações, como expressaram: "[utilizo] minimamente, por ser analfabeto digital. As redes, os aplicativos são de extrema importância para a vida acadêmica"; "[...] estou começando a aprender justamente pela universidade".

Dois alunos $(\mathrm{N}=2)$ mencionaram em seus questionários 0 fato de se considerarem "analfabetos digitais" e nas observações, também constatamos que alguns sentiam grande dificuldade quando o trabalho demandava uso de recursos de informática, alegando não saber digitar direito, ter pouco contato com a ferramenta Word e também não ter apoio de terceiros em outros espaços para além da Universidade para pedir ajuda. Com isso, a noção de capital de rede nos ajuda a compreender que, mesmo que digam que possuem acesso, seus usos ainda são em grande medida muito restritos. 
Os/as alunos/as reconhecem que grande parte dos docentes utilizam tecnologias em suas aulas, sobretudo o Datashow para apresentações de slides (o que, em sua visão, auxilia, mas não é suficiente para tornar uma aula mais acessível). Contudo, pudemos registrar as dificuldades que se colocavam quando docentes disponibilizavam materiais didáticos somente em plataformas digitais, como e-mails e páginas de Internet. $\mathrm{O}$ registro desse aluno em seu questionário foi bem emblemático:

[...] em minha opinião nem todo mundo tem acesso ao computador, internet, etc. em casa. Algumas disciplinas fazem uso de slides e colocam no e-mail da turma para alguns é um adianto, mas para outros não é isso fica complicado. Tive uma disciplina de tecnologias que o uso do computador era bem restrito, pois só acessava o Google e e-mail. Outros usos nós fazíamos em casa (R. 57 anos, 7. p.).

Em nossas observações, os usos das tecnologias móveis foi um aspecto que mereceu destaque, além de ter sido consensual sua utilidade. Embora nem sequer possuam computadores em suas casas, os discentes acessam Internet através de Smartphones para finalidades das mais diversas, para além das acadêmicas.

A turma de terceiro período de 2016.1 foi observada sistematicamente ao longo do período e consta em nossos registros o quanto a turma usava tecnologias no dia a dia acadêmico. O WhatsApp da turma funcionava muito bem para a comunicação imediata entre os estudantes, seja para informarem uns aos outros se vai ter aula, se é possível faltar ou não, comemorações, trânsito, textos, comunicados entre outras coisas. No e-mail, conseguiram manter um fluxo de contato com os professores, tanto para o envio de textos como também anúncios e comunicados sobre congressos, bolsas, dentre outros. Nesse também era armazenado todos os textos passados por períodos para que pudessem sempre ter acesso, ainda mais aqueles que deixam matérias para trás. Fizemos o seguinte registro:

Durante as aulas, foi possível observar que os Smartphones eram usados não apenas para conversas no WhatsApp, mas também para acompanhar textos, tirar fotos dos slides, anotações e até dos próprios livros dos professores. Mesmo assim, os alunos faziam questão de que fosse deixado também na xerox por conta de alunos que não eram da turma e também dos que preferiam e tinham condições de ter impresso. Quanto a isso, os próprios se solidarizavam e tiravam xerox em casa ou no trabalho para seus mais próximos ou scaneavam. Para não perder aula para tirar xerox quando preciso, já que a mesma fechava cedo e os horários eram 
apertados, um aluno pegava o dinheiro de quem queria e ia durante uma aula tirar para todos (Caderno de Campo, Turma 3, 3.período, 2016.1)

O período de 2016.2, por ter sido bastante atípico (contou apenas com três meses) e um encurtamento das aulas, foi se agravando com o passar do tempo muito em função dos salários docentes que não estava sendo pago. Alguns docentes optaram por concentrar sua comunicação com as turmas por meio dos recursos digitais. Registramos em caderno de campo que uma turma teve grandes dificuldades quando o docente concentrou em um site todo o seu material didático das aulas. Para acessar, cada discente precisava criar um login e senha com sua matrícula. A turma alegava motivos diversos, mas dizia não conseguir o acesso.

Foi um consenso nas respostas que os discentes não são favoráveis à ideia de se restringir a produção e envio de trabalhos que dependam do uso exclusivamente de Internet. Os alunos e alunas demonstravam descontentamento quando os docentes só aceitavam trabalhos entregues em mãos e com datas marcadas, liberando o envio por e-mail apenas para os/as alunos/as cotistas. 0 alunado defendia que era necessário ter as duas vias de entrega de trabalho disponíveis para todos/as.

Os discentes, por sua vez, também faziam amplo uso de e-mails. Convenciona-se que cada turma crie um e-mail e que os docentes enviem material para este, o que torna uma tarefa complexa para os alunos e alunas que fazem apenas uma disciplina na turma, não tendo acesso a este login e senha. Quando comunicam o fato, os docentes geralmente se colocam dispostos a enviar os e-mails também para estes/as. Grupos de WhatsApp e Facebook das turmas também são recursos bastante utilizados para organizar trabalhos em grupo, trocar textos, informações e organizar tarefas.

Entre aqueles/as matriculados/as no primeiro e terceiro período da faculdade, pudemos perceber o desconhecimento da localização de espaços que contavam com computadores para uso (a biblioteca é um deles, possuindo alguns netbooks disponíveis para estudantes) e as condições para usarem tais recursos.

Alguns apontamentos se encaminharam para questões mais técnicas, como as da aluna R. de 21 anos, do quinto período:

[...] Acredito que as pessoas tenham o domínio das tecnologias, mas as dificuldades com a falta de conhecimento da estrutura local (no caso a estrutura do computador na universidade) atrapalham o uso dos mesmos (R. 21 anos, 5. p.). 
DOI: $10.12957 /$ e-mosaicos.2017.30009 existentes:

A aluna também apresentou propostas para um melhor uso dos recursos

A facilidade é que temos os equipamentos. As dificuldades são que estes equipamentos são de uso coletivo, e as pessoas acabam mexendo e as vezes mudando conexões ou configurações do sistema, e nós, sem saber dessas alterações acabamos perdendo tempo para utilizar as tecnologias a nossa disposição. Outra dificuldade é a conexão com a Internet. Temos vários Wi-fi, mas as senhas não são acessíveis por todos e isso, na minha opinião, atrapalha muito. Deve ser feita uma catalogação dos Wi-fi disponíveis com as suas respectivas senhas e entregue aos professores para que eles possam ter um acesso com maior facilidade (R. 21 anos, 5. p.).

Ao mesmo tempo em que são incluídos a partir do momento em que estão conectados/as nestas redes digitais, também podem se sentir, nos termos de Bourdieu e Champagne (1998), "excluídos do interior" da instituição, ao não dominarem os novos códigos demandados pela mesma. A aluna J., de 44 anos, cursando o sétimo período, relata ter muitas dificuldades para o uso das novas tecnologias na Universidade, sendo essas muito mais um elemento que lhe traz problemas. Sente falta de uma formação integrada aos recursos tecnológicos, chegando a afirmar: "Seria bem interessante e oportuno uma disciplina, uma eletiva que oportunizasse uma alfabetização digital".

No que se refere à percepção da relação dos docentes em relação aos usos dos recursos tecnológicos, o grupo fez algumas sinalizações bastante relevantes. Por exemplo, a aluna R., de 21 anos, do quinto período, chega a utilizar o termo "aversão" para tratar desta relação: "Alguns professores vejo que tem aversão, mas a maioria adere ao uso das tecnologias [...]" (R. 21 anos, quinto período). A aluna A., 31 anos, do oitavo período, se expressa de forma um tanto quanto semelhante: "Acredito que boa parte dos docentes ainda resiste em usar as novas tecnologias em sala e fora da sala devido ao preconceito que existe sobre as novas tecnologias [...]" (A. 31 anos, oitavo período).

Uma das entrevistadas comenta que além das dificuldades técnicas, a relação também não é das mais simples. Ela indica que esta é

"[...] Difícil. Não temos acesso à internet para os alunos. Os computadores das salas não funcionam bem. E quando alguns alunos levam seus textos em PDF no tablet ou celular, alguns professores pedem que o mesmo guarde, e o aluno fica sem conseguir acompanhar a aula" (G. 22 anos, oitavo período). 
Com base nas análises discentes, pude perceber que por mais que os discentes se interessem por discutir e trazer estas novas formas de comunicação para suas salas de aula, persistem as resistências docentes ao uso dos recursos tecnológicos, em consonância com o que sinaliza Silva (2003). O autor constata a existência de um fenômeno que ele denomina "tecnofobia" (SILVA, 2003, p.15), por parte de muitos/as docentes. O termo se refere à recusa a qualquer tecnologia de natureza elétrica ou eletrônica e o que ele também identifica como certo "mal-estar docente" (uma confusão frente ao variado conjunto de tecnologias atualmente disponíveis).

Com resistências e insistências, tanto por parte de professores/as e alunos/as, de diversas formas os recursos tecnológicos adentram em nossas Universidades. 0 que nos falta ainda talvez seja como negociar e integrar os potenciais criativos e inventivos tanto por parte dos recursos, como de seus usuários. Com isso, novos processos de ensino e aprendizado tendem a se organizar, talvez (des)organizando práticas mais convencionais e nos fazendo repensar nossa atividade docente cotidianamente.

\section{Algumas Considerações}

Apesar de entendermos que existem diferentes formas pelas quais os discentes acessam os recursos tecnológicos para suas atividades acadêmicas e extraacadêmicas, muitos/as ainda se sentem "excluídos no interior", nos dizeres de Pierre Bourdieu e Patrick Champagne (2007), por não disporem deste "capital de rede" ao qual se referiam Elliot e Urry (2010).

Entendendo que as diferenças e as desigualdades de acesso e uso (GARCÍA CANCLINI, 2007) existentes não só em nível local, mas também global são imensas, o que nos faz identificar a existência destes "excluídos no interior das salas de aula" (BOURDIEU; CHAMPAGNE, 1998) e como sua desconexão se faz presente. Ou seja, em tempos em que tantos/as não se imaginam offline, outros tantos/as pouco ou nunca ficam online.

São novos desafios que se colocam para uma sociedade que cada vez mais entende a cidadania como diretamente atrelada ao consumo de bens materiais e simbólicos (GARCÍA-CANCLINI, 1999), e este consumo excessivo - que não é igual para todos/as - é encarado como um dos nós que retardam a marcha do progresso, dada a perversidade com que exclui grande parte da população de seus benefícios. Esta avaliação do autor fica bem em consonância com um escrito bastante incisivo de uma de nossas alunas, nos levando a questionar muito a linha tênue entre um uso destes veículos tecnológicos que aproxima e outro que igualmente também pode segregar: "Nos tornamos uma aldeia global, porém que nos segrega e aparta cada vez mais" (S. 27 anos, sétimo período).

A mobilidade, tal como a entendem Elliot e Urry (2010), pode ser considerada um importante fenômeno da sociedade contemporânea. Trata-se de um elemento 
fundamental da vida cotidiana que se relaciona com a capacidade de experimentar a mobilidade reorganiza a vida social e define a sociedade contemporânea como uma sociedade que está permanentemente em movimento, e por isso deve ser analisada a partir do ponto de vista da experiência da circulação.

Para além de discussões que se antagonizam entre malefícios ou benefícios supostos pelas interações virtuais, o que nos interessa é analisar, a partir de trajetórias e contextos de alunos e alunas, como se dão suas relações com estes recursos, seus níveis de capital de rede e possibilidade de mobilidade e/ou imobilidade nesta lógica das redes. (URRY, 2000, 207, 2010).

Estabelecendo um diálogo que Elliot e Urry (2010) fazem com Zygmunt Bauman, percebemos que há muitos pontos em comum entre a noção de liquidez generalizada discutida por Bauman e a concepção das mobilidades. Atento aos aspectos questionáveis dos novos tipos de interações sociais, o autor não se furtou a faze críticas à suposta volatilidade de nossas relações humanas, que estavam "perdendo o trem da história" para as tecnologias.

Bauman indica que é o grau de mobilidade, ou seja, é a liberdade para escolher onde estar, que estratifica seus membros (BAUMAN, 1999, p. 94). Isso equivale a afirmar que apesar da evolução tecnológica - seja no âmbito do transporte ou da informação -, a mobilidade física reflete e reforça as desigualdades sociais.

Embora a Universidade lide com um público de alunos/as diversificado, com um grupo bastante conectado que em sua maioria nos demonstrou ter facilidade com a cultura digital, alguns não dispunham desses recursos, nos termos de Bourdieu (1998), desse capital cultural herdado, ou nos dizeres de Elliot e Urry (2010), desse capital de rede, percebemos que muito ainda há que se avançar para que este contingente de discentes que são "excluídos no interior", possam se sentir integrados e que as tecnologias, não sejam utilizadas para afastá-los, mas ao contrário, para uni-los cada vez mais e tornando-se potencias criadoras e criativas nos processos de ensino e aprendizado.

\section{REFERÊNCIAS BibLIOGRÁfICAS}

BAUMAN, Zygmunt. Globalização: as consequências humanas. Rio de Janeiro: Jorge Zahar, 1999.

BOURDIEU, Pierre. A escola conservadora: as desigualdades frente à escola e à cultura. In: NOGUEIRA, M. A.; CATTANI, A. (org.). Escritos de Educação. Petrópolis: Vozes, 1998. p. 39-64.

; CHAMPAGNE, Patrick. Os excluídos do interior. In: NOGUEIRA, M. A.; CATTANI, A. (org.). Escritos de Educação. Petrópolis: Vozes, 1998. p. 217-227.

CASTELLS, M. A sociedade em rede. São Paulo: Editora Paz e Terra, 1999, vol. I. 
DOI: $10.12957 /$ e-mosaicos.2017.30009

. O poder da identidade. São Paulo: Editora Paz e Terra, 2008, 6.ed., vol. II. . Fim de milênio. São Paulo: Editora Paz e Terra, 2012, vol. III.

- A galáxia da Internet. reflexões sobre a Internet, os negócios e a sociedade.

Rio de Janeiro, Zahar, 2003.

. Redes de indignação e esperança: movimentos sociais na era da Internet. Rio de Janeiro: Zahar, 2013.

ELLIOTT, A.; URRY, J. Mobile Lives. Londres: Routledge, 2010.

GARCÍA CANCLINI, Néstor. Diferentes, desiguais e desconectados. 2. ed. Rio de Janeiro: Editora UFRJ, 2007.

LEMOS, R; DI FELICE, M. $A$ vida em rede. Campinas, SP: Papirus 7 Mares, 2014.

LÉVY, Pierre. Cibercultura. São Paulo: Ed. 34, 2000.

. A inteligência coletiva. São Paulo: Edições Loyola, 2007.

. As tecnologias da inteligência: o futuro do pensamento na era da informática. Rio de Janeiro: Ed. 34, 2008.

MAFFESOLI, Michel. O tempo das tribos. o declínio do individualismo nas sociedades de massa. Rio de Janeiro: Forense Universitária, 2010.

SOUZA e SILVA, J. "Por que uns e não outros": caminhada de jovens pobres para a universidade. Rio de Janeiro: 7 Letras, 2003.

. A observação do cotidiano escolar. In: ZAGO, N.; CARVALHO, M. P.; VILELA, R. A. T. (orgs.). Itinerários de pesquisa qualitativa em sociologia da educação. Rio de Janeiro: Lamparina, 2011, p. 183-206.

TURA, Maria de Lourdes Rangel; SILVA, S. M. Etnografia da prática pedagógica em contextos de multiculturalidade: o caso de uma Escola do Rio de Janeiro e de uma Escola do Porto. In: TURA, Maria de Lourdes Rangel; LEITE, Carlinda (Orgs.). Questões de currículo e trabalho docente. Rio de Janeiro: Quartet / FAPERJ, 2010, p. 71-105.

URRY, J. Sociology Beyond Societies. Mobilities for the twenty-first century. London: Routlegde, 2000.

. Mobilities. Cambridge: Polity Press, 2007. 